\title{
¿ECONOMÍA HETERODOXA O ECONOMÍA POLÍTICA?
}

Frank Stilwell

Siete años después del inicio de la crisis financiera global, cuando se dijo que el pensamiento económico ortodoxo había fracasado y debía cambiar, es evidente que no ha habido cambios decisivos. Algunos dirían que nada ha cambiado. Esto no solo sucede en la academia, donde los cursos básicos de los departamentos de economía siguen subrayando la formación básica (algunos dirían el adoctrinamiento) en los principios de la economía neoclásica. También es evidente en el campo de la política económica, que sigue dominado por la agenda neoliberal, ampliada por la política de austeridad posterior al colapso. Debido a esta capacidad de recuperación de la economía convencional es esencial que los disidentes reconsideren cómo cuestionar mejor la ortodoxia en la teoría y la práctica.

Los participantes activos en la RWER reconocen que la economía convencional es inadecuada y que se necesitan alternativas progresistas en la formación económica, el debate público y la formulación de políticas. ¿Pero cómo lograr ese avance? Una lección de la lucha por establecer programas de enseñanza e investigación alternativos es que es sumamente difícil establecerlos en el territorio que ocupan los economistas ortodoxos. La intervención en el discurso público más amplio es también un gran desafío, dados los intereses creados y las instituciones que determinan su dirección. Para la estrategia futura se deben examinar algunas preguntas de fondo.

* Profesor emérito, Departamento de Economía Política, Universidad de Sídney, Sídney, Australia, [frank.stilwell@sydney.edu.au]. Tomado de Real World Economics Review (RWER) 74, abril de 2016, pp. 42-48. Se publica con las autorizaciones correspondientes. Traducción de Alberto Supelano. Fecha de recepción: 15 de abril de 2016, fecha de aceptación: 12 de mayo de 2016. Sugerencia de citación: Stilwell, F. “¿Economía heterodoxa o economía política?”, Revista de Economía Institucional 18, 34, 2016, pp. 283-292. DOI: http://dx.doi.org/10.18601/01245996.v18n34.15 
En este contexto las etiquetas son importantes, igual que en el mercadeo. Crean imágenes y señalan elecciones estratégicas. Las dos etiquetas a las que se refiere este artículo son "economía heterodoxa" y “economía política”. ¿Es mejor desafiar a la economía convencional bajo la primera enseña o bajo la segunda? ¿Esos términos son sinónimos? ¿Es un simple asunto de terminología? O la pregunta atañe a una decisión estratégica más importante: ¿buscar espacio para la investigación y la enseñanza de la economía no neoclásica o promover la economía política como parte de un proyecto interdisciplinario, social y político más amplio? Los grupos disidentes suelen afrontar las preguntas de enfoque y auto identificación y mucho depende de ellas. Aunque la terminología no es esencial en sí misma, tiene implicaciones para la estrategia.

Este artículo argumenta en favor de la economía política y expone cinco razones relacionadas con el pluralismo, la política, el estatus profesional, las asociaciones académicas y el reconocimiento público.

\section{LA IDENTIFICACIÓN COMO PLURALISTAS}

La necesidad de una perspectiva pluralista, tanto en la formación económica como en la formulación de políticas, es aceptada por los críticos de la ortodoxia. Debido a que el monismo de la ortodoxia es el problema, el pluralismo es la solución. Este argumento ha sido elaborado extensamente en las dos últimas décadas, incluso en mis propios escritos. Como argumenta John King, "la economía es la única ciencia social en la que predomina una corriente monolítica única, que desconoce o es abiertamente hostil a los enfoques alternativos" $(2013,17)$. En la educación esto tiene consecuencias infortunadas, pues limita la comprensión de los procesos y hechos político económicos. Margina el estudio de la historia económica y de la historia del pensamiento económico, lo que genera un enfoque ahistórico que produce una especie de amnesia profesional. Aún peor, tiene resultados sociales perjudiciales, como las políticas disfuncionales promulgadas en nombre de una "economía sana" desde el inicio de la crisis financiera global. Al mismo tiempo, los procesos oficiales de evaluación de la investigación universitaria marginan los enfoques no convencionales, lo que agrava los problemas antes mencionados. Este es un proceso de causación circular acumulativa, por el cual el monismo convencional excluye los elementos que podrían mejorar las explicaciones de los fenómenos económicos del mundo real. Es un ciclo vicioso. Solo puede corregirlo la adopción general del pluralismo. 
Cabría pensar que tales observaciones apoyan el argumento de desafiar a la economía convencional bajo la enseña de "economía heterodoxa”. Según ese razonamiento, auto identificarse como economistas heterodoxos indica la preocupación de que las opiniones convencionales tengan mejor recibo como análisis alternativo del funcionamiento del mundo real. En la práctica, esto significa enfrentar la economía neoclásica predominante con las opciones críticas, incluidas las diversas vertientes de la economía postkeynesiana, marxista e institucional, y con las perspectivas feminista, ecológica y otras más. Esto es de hecho lo que hacen los economistas heterodoxos. Además, la etiqueta "economía heterodoxa" encaja bien con la pretensión de establecer prácticas académicas que propicien una "sociedad abierta" en la que exista libertad de expresión y florezcan la innovación y la creatividad. Es también un antídoto contra la pretensión de los políticos de derecha de que "no hay alternativa".

Pero un examen más cuidadoso muestra que confundir el argumento en favor del pluralismo con la defensa de la economía heterodoxa crea tres problemas espinosos.

Primero, heterodoxia y pluralismo no son sinónimos. El pluralismo es una posición metodológica que acepta la diversidad por principio: normalmente incluiría el pensamiento predominante y una amplia gama de puntos de vista distintos. Por su parte, la heterodoxia implica oposición a la ortodoxia, pero los economistas heterodoxos también pueden ser hostiles a enfoques diferentes del que prefieren. En la lucha por el avance de la economía, puede parecer que heterodoxia y pluralismo son parientes cercanos, pero es pertinente identificar esta diferencia conceptual. El pluralismo es una actitud "de principios", basada en proposiciones ontológicas, epistemológicas y éticas (como señalan Mariyani y Moussa, 2015), mientras que el movimiento por la economía heterodoxa busca, pragmáticamente, crear espacios para las alternativas a la ortodoxia que se prefieren.

Segundo, ¿qué alternativas deberían conseguir esa audiencia? ¿Qué se debería incluir en la "economía heterodoxa"? Parece haber consenso sobre las contribuciones de la economía marxista, postkeynesiana e institucional. También se apoya la aceptación de la economía ecológica y la economía feminista, aunque los economistas neoclásicos también afirman su presencia en estos campos. Pero ¿qué hacer con la economía austríaca, con sus implicaciones libertarias de derecha de "libre mercado"? ¿También se debería incluir? Y los aportes de las tradiciones de Karl Polanyi o Henry George, ¿no deberían entrar también en la mezcla? Una "economía heterodoxa" que simplemente 
acomode todos estos elementos puede ser muy ecléctica, lo que potencialmente disiparía o quitaría filo al desafío al paradigma neoclásico. Para avanzar puede ser necesaria una concepción más sólida de "unidad en la diversidad".

$\mathrm{E} 1$ tercer problema es que algunos economistas dicen que la corriente dominante ya se ha vuelto heterodoxa. Diana Coyle (2007) y David Colander (2009) sostienen esta opinión; plantean que la teoría de juegos, la nueva teoría del crecimiento, la economía del comportamiento y experimental, la economía de la complejidad y otras innovaciones teóricas han mermado el predominio neoclásico (Thornton, 2015). En lo personal, considero que este argumento no es convincente, al menos por tres razones. Primera, aunque estos desarrollos analíticos dan la apariencia de diversidad en el pensamiento convencional, mantienen los supuestos subyacentes del individualismo metodológico y de la estabilidad sistémica a través de las fuerzas del mercado. Invocar la novedad del pluralismo en la economía neoclásica como respuesta a sus deficiencias es ignorar la diversidad que ha caracterizado a la disciplina desde sus comienzos, sin que esta implique siempre un cambio de paradigma o una ruptura radical con esos supuestos. Segunda, estos elementos de diferenciación del producto no han desplazado a la economía neoclásica en el currículo básico que se enseña a los estudiantes, aunque a menudo sean la base de las materias electivas en los últimos años de estudio. Puesto que lo que se enseña en los años de fundamentación es la base sobre la que se definen y reproducen la disciplina y la profesión, esos cambios no son fundamentales ni transformadores. Tercera, si una profesión académica se juzga en últimas por su influencia y sus efectos externos, es evidente que "no ha habido cambios" en una economía ortodoxa que funciona como ideología capitalista. La estrecha asociación entre neoclasicismo en la academia y neoliberalismo en la política pública así lo evidencia. Incluso Diane Coyle, célebre por su énfasis anterior en la flexibilidad de la disciplina, admite que el impacto catastrófico de la crisis financiera global ha tenido poco impacto en cómo se construye y reproduce la ortodoxia académica (Coyle, 2013). No obstante, afirmar que hay una "heterodoxia interna" en la economía convencional enturbia las aguas. Quizá ese sea el propósito.

Estas observaciones ilustran la importancia del pluralismo en el desafío a la ortodoxia, también muestran algunas tensiones asociadas. La búsqueda de mayor unidad, analítica y organizativa, sería de gran ayuda en una situación de conflicto como esta. Esto implica trabajar en conjunto para difundir y ampliar la crítica de la economía conven- 
cional y desafiar su influencia, tanto entre los estudiantes como en el mundo del discurso económico y la política pública. Al mismo tiempo, la búsqueda de elementos comunes, incluso de síntesis parciales, entre las principales corrientes progresistas no neoclásicas es necesaria para desarrollar alternativas efectivas e influyentes. Las siguientes consideraciones indican por qué la adopción de una "economía política" más amplia puede contribuir a esa estrategia más aseverativa para desafiar el pensamiento predominante.

\section{SER EXPLÍCITAMENTE POLÍTICOS}

La auto identificación como movimiento por la "economía política" indica de por sí el carácter político del empeño y desafía expresamente la pretensión de los economistas convencionales de seguir líneas de investigación "libres de valores". Hablar de economía política lleva necesariamente e preguntar “¿qué política?” y “¿qué valores?”También señala la búsqueda de puntos comunes entre las corrientes que critican el pensamiento convencional. Este terreno compartido puede ser ontológico, como ha insistido Tony Lawson en su defensa del enfoque realista crítico (Lawson, 2006; Morgan, 2016). Así, la unidad puede provenir de una "visión" de la economía capitalista estructurada por relaciones de poder y propensa a la desigualdad y la crisis. El terreno común también puede ser metodológico: enfatizar el compromiso compartido con el análisis del carácter históricamente contingente de los fenómenos económicos en vez del análisis de las condiciones de "equilibrio". Y también puede ser explícitamente político: subrayar la misión de poner la política democrática al mando de las fuerzas de mercado, como proponen Higgins y Dow (2105). Pueden ser y quizá deberían ser todos los tres.

Pese a las pretensiones y protestas convencionales, la economía dominante es intrínsecamente política y cargada de valores. De modo que también es desafiante y cambiante. Señalar esto en la enseña del desafío es un antídoto saludable contra la pretensión espuria de que la economía es una ciencia libre de valores. Como subrayó Gunnar Myrdal (1953), el desarrollo del pensamiento económico siempre y en todas partes ha tenido un carácter político. La economía y la política están entrelazadas en el mundo real. Por ello, el cuestionamiento exitoso de la ortodoxia dominante no puede ser tan solo un asunto de desarrollar "mejores" modelos económicos (reivindicar una mayor capacidad explicativa). También tiene que ser un proceso político. 


\section{AFIRMACIÓN DEL ESTATUS PROFESIONAL}

Otra ventaja del término "economía política" es su extenso y respetable linaje. En efecto, la economía política, que afirma ser la corriente principal de pensamiento desde el siglo XVIII hasta el siglo XXI, incluye las contribuciones seminales de Smith, Ricardo, Marx, Veblen, Keynes, Kalecki, Robinson, Myrdal, Galbraith, Heilbroner y de autores modernos a esa amplia tradición de la investigación social. Desde esta perspectiva, la economía neoclásica se puede considerar como un desvío inicialmente interesante que se convirtió en un callejón sin salida (aunque con gran volumen de tráfico).

Esta afirmación del estatus y la centralidad de la economía política es impugnada por los economistas convencionales. Si llegan a mencionar el término economía política, lo tratan usualmente como algo de simple interés histórico, relacionado con las características de la investigación económica en una época pre-científica. O que solo se refiere al análisis y la prescripción de la política pública. Ese uso que le dan los economistas asociados a la escuela de Virginia, a la escuela de Chicago y a la teoría contemporánea de la "elección pública" es una fuente común de confusión, en particular en Estados Unidos. En el uso histórico, el término economía política también denota la preocupación por políticas que puedan modificar o regular el funcionamiento de la economía en busca de objetivos sociales específicos, en contraste con la economía como el estudio de cómo funciona la economía. Estas son dificultades terminológicas que, de nuevo, infortunadamente enturbian las aguas. Sin embargo, tratar de evitar estos problemas retirándose a la "economía heterodoxa" es aceptar un estatus marginal, como si fuese todo lo que se le puede ofrecer. Eso es lo que indica la inclusión usual (en el mejor de los casos), en la clasificación de la publicaciones oficiales, de la "economía heterodoxa" en la categoría residual "otras economías”. Desafiar esta marginación y definir una agenda positiva para el análisis económico alternativo, en vez de reaccionar simplemente al pensamiento convencional, es una preocupación sustancial de largo plazo que requiere redefinir el territorio relevante; desafiando el carácter y los límites de la disciplina.

\section{CONSTRUIR ASOCIACIONES INTERDISCIPLINARIAS}

Aunque la profesión siga eludiendo los retos planteados por los economistas heterodoxos, se pueden lograr avances sustanciales en relación con las ciencias sociales afines. Este es un elemento necesario en una 
estrategia para el progreso porque los economistas convencionales que trabajan en las universidades suelen oponerse a los intentos de reconstituir su disciplina sobre principios auténticamente pluralistas. La economía política marxista, por ejemplo, usualmente solo puede conseguir audiencia como una visión históricamente desacreditada; mientras que el "viejo" institucionalismo, si es mencionado, es un simple precursor de "la nueva economía institucional" más compatible con el enfoque neoclásico. Los economistas heterodoxos pueden conseguir empleo en departamentos de economía: algunos lo consiguen, especialmente si su "desviación" se desarrolla después de haber conseguido un empleo seguro, pero a menudo no son sustituidos por personas de inclinación similar cuando se jubilan o se van.

Establecer un territorio más seguro para enseñar e investigar en economía política puede ser más fácil en otros campos de las ciencias sociales donde hay interés por las dimensiones económicas de los problemas sociales y la política pública. En mi experiencia, los economistas políticos son bien acogidos en estos campos (si evitan la ambición imperialista que es evidente cuando los economistas neoclásicos intentan invadir otros dominios de las ciencias sociales). Así, lo esencial es la relación de aprendizaje mutuo entre la economía y disciplinas como la sociología, la geografía, la política o la historia. En la construcción de esas asociaciones es más importante el compromiso con los estudios interdisciplinarios que el compromiso con el pluralismo en economía.

En otras palabras, establecer puntos de apoyo para la economía política, bien sea en un departamento separado del de economía (como el Departamento de Economía Política de la Universidad de Sídney, donde enseñé durante más de cuatro décadas) o en conjunto con otras ciencias sociales, es un requisito para que la economía heterodoxa tenga un lugar sostenible en la enseñanza y en la investigación. Después de establecer esos puntos de apoyo, la buena enseñanza puede demostrar que la economía política tiene potencial para proporcionar un aprendizaje más enriquecedor que la economía convencional (O’Donnell, 2014). Del mismo modo, la investigación y la defensa de políticas usualmente pueden conseguir una buena audiencia donde los economistas políticos contribuyen a estudios interdisciplinarios sobre asuntos de importancia e interés público.

\section{LOGRAR RECONOCIMIENTO PÚBLICO}

El desafío a la economía ortodoxa siempre será marginal si sigue siendo una preocupación puramente académica. Más allá de las uni- 
versidades hay medios importantes de influencia pública. La educación en el movimiento laboral es uno de ellos (Stanford, 2015). También es necesario escribir sobre economía política para revistas populares y sitios web, así como participar en los medios de comunicación y trabajar con partidos políticos y ONG progresistas. Preparar informes para las indagaciones del gobierno -y usar ese material en escritos académicos o periodísticos- es una actividad que se ajusta bien a esta estrategia. Para restar influencia a la economía convencional es esencial estar en sintonía con las preocupaciones del público más amplio y tener una identidad que este reconozca.

A este último respecto, el término "economía política" aventaja al de "economía heterodoxa”. Economía política indica una concepción amplia de cómo se entiende la economía en un contexto histórico, social y político. Tiene más potencial para el reconocimiento público y es una etiqueta razonablemente comprensible para los no especialistas. En este sentido contrasta con la respuesta típica del público cuando escucha el término “economía heterodoxa”: “Hum!, ¿qué es eso?”.

\section{CONCLUSIÓN}

El desafío a la economía convencional no produce un choque simple o directo, como el de dos equipos que intentan anotar más carreras o goles para determinar al ganador. Las reglas de la contienda no se acuerdan de antemano y no hay una arena aceptada ni un árbitro imparcial. Incluso los criterios para juzgar el éxito son discutibles.

Para los economistas disidentes autodenominarse heterodoxo es académicamente respetable, pero puede ser estratégicamente débil. En el lado positivo, la gran ventaja del término heterodoxia es su asociación con el pluralismo, que indica aversión al dogma y apertura a formas alternativas de ver el mundo. Pero hay una tensión entre el pluralismo y la economía heterodoxa, como argumento en este artículo. El problema estratégico es que defender la heterodoxia supone el papel central de una ortodoxia: por ello, casi por definición queda consignada al exterior. Esto tiende a poner "a la defensiva" a los defensores de la economía heterodoxa y a buscar refugio para una gama de puntos de vista diferentes, sea cual sea su coherencia o su relación mutua. Luchar por que la economía política tenga un lugar central en el discurso económico es una estrategia más afirmativa. Es compatible con el pluralismo, pero hace más énfasis en la unidad en la diversidad, en los elementos políticos que inspiran a las corrientes alternativas de pensamiento económico, en el potencial para ganar 
fuerza mediante asociaciones interdisciplinarias y en la necesidad de reconocimiento e influencia públicos más amplios.

No presento estas opiniones con la esperanza de que los individuos y las asociaciones abandonen su identificación actual como "economistas heterodoxos". Ese no es el punto principal de este artículo. Es, más bien, situar a la economía heterodoxa como parte de un proyecto de economía política más amplio interesado en entender cómo funcionan las economías en relación con los procesos sociales, y en desarrollar prácticas políticas que puedan contribuir a arreglos más equitativos $y$ sostenibles en el futuro. Este es un proyecto intrínsecamente interdisciplinario y explícitamente político. Es necesario porque se opone a una ortodoxia económica engañosa con sesgo clasista, y debido a su crítica del "capitalismo realmente existente" y de las prácticas políticas neoliberales en el conjunto de la sociedad. Este proyecto de economía política no puede ser una preocupación exclusivamente académica, en parte por las restricciones que existen dentro de la academia y, en forma más positiva, porque la sociedad lo necesita. Por cierto, bien sea bajo la enseña de economía heterodoxa o de economía política, hay mucho trabajo por hacer.

\section{REFERENCIAS BIBLIOGRÁFICAS}

1. Colander, D. "Moving beyond the rhetoric of pluralism: Suggestions for an 'inside the mainstream' heterodoxy", R. Garnett et al., eds., Economic pluralism, Londres y Nueva York, Routledge, 2009.

2. Coyle, D. The soulful science: What economists really do and why it matters, Princeton, Princeton University Press, 2007.

3. Coyle, D. "The state of economics and the education of economists", WEA curriculum conference The economics curriculum: Towards a radical reformulation, 2013, [http://curriculumconference2013.weaconferences. net/papers/the-state-of-economics-and-the-education-of-economists].

4. Higgins, W. y G. Dow. Politics against pessimism, Berna, Peter Lang, 2013.

5. King, J. E. “A case for pluralism in economics”, Economics and Labour Relations Review 24, 2013, pp. 17-31.

6. Lawson, T. "The nature of heterodox economics", Cambridge Journal of Economics 230, 2, 2006, pp. 483-507.

7. Mariyani-S., E. y M. Moussa. "Fallibilism, liberalism and Stilwell's advocacy for pluralism in economics", Journal of Australian Political Economy 75, 2015, pp. 194-210.

8. Morgan, J. "The continued relevance of neoclassical economics and the mainstream", World Economics Association Newsletter, enero de 2016, [www.worldeconomicsassociation.org/newsletterarticles/relevance-ofneoclassicism].

9. Myrdal, G. The political element in the development of economic theory, Londres, Routledge and Kegan, 1953. 
10. O'Donnell, R. "What do graduate attributes have to do with political economy?", S. K. Schroeder y L. Chester, eds., Challenging the orthodoxy: The contributions of Frank Stilwell to political economy, Heidelberg, Springer, 2014.

11. Stanford, J. "Towards an activist pedagogy in heterodox economics: The case of trade union training", Journal of Australian Political Economy 75, 2015, pp. 233-256.

12. Stilwell, F. "Editorial: Heterodox economics and political economy", Journal of Australian Political Economy 75, 2015, pp. 5-10.

13. Thornton, T. "The changing face of mainstream economics", Journal of Australian Political Economy 75, 2015, pp. 11-26. 